\title{
The main aspects of andrological evaluation of bucks
}

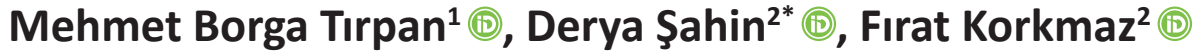 \\ ${ }^{1}$ Ankara University, Faculty of Veterinary Medicine, Department of Reproduction and Artificial Insemination, Ankara, Turkey \\ ${ }^{2}$ International Center for Livestock Research and Training, Laboratory of Artificial Insemination, Ankara, Turkey
}

\section{Article History}

Received: 03 July 2020

Accepted: 19 November 2020

First Online: 25 December 2020

\section{Corresponding Author}

Tel.: +903128651196

E-mail: vh.sahinderya@outlook.com

\section{Keywords}

Andrological evaluation examination Assisted reproductive technologies Breeding soundness examination Goat

\begin{abstract}
Goat breeding has economic importance specifically in developing countries in terms of fiber, milk, and meat production. To reach the increasing market demands, a thoroughly organized breeding program is required. While most breeders focus on the female part of reproduction management, male selection constitutes the overlooked half. However, this forgotten part should begin with male selection through an andrological evaluation examination (Breeding soundness exam (BSE)). After the male selection, semen collected from these bucks can be transported to other herds easily and genetic advance can be achieved in a shorter period with the help of assisted reproductive techniques. Using selected males' semen with artificial insemination (Al) in goats can bring huge improvement at goat breeding with its rapid and reform triggering effects. However, there are still missing pieces in terms of andrological examination evaluation and assisted reproductive techniques in goats and future research is still required to complete this puzzle. This review will focus on the selection of bucks and the advances in most commonly used assisted reproduction techniques in the field level.
\end{abstract}

\section{Introduction}

Goats have considerable economic importance and triggering impact in a wide scope of rural production systems (Fatet et al., 2011), especially in developing countries. Their natural ability to use pastures and water efficiently and have a higher resistance to heat and cold stress allows it to be easily bred in a variety of climatic and geographical conditions (Gebre, 2007; Delgadillo et al., 1997). Additionally, its cultural role in some societies can not be ignored by explaining its spreading on the earth. In a temperate climate, they are mainly used for dairy, but they can also be used for meat and fiber production. In this zone, goats are seasonally polyestrous animals. The length of the sexual season varies with day length, latitude, climate, breed, nutrition, presence or absence of male and other unknown conditions. The main environmental factor affecting the sexual season of goats in temperate regions is the alterations in day length, which is called photoperiodism. Moreover, the largeness of serum gonadotropin and testosterone se- cretion of mature bucks in response to day length changes show breed differences. Additionally, does' follicular activity changes during the year in depending on the prolactin secretion and photoperiodism as similar bucks.

In bucks, puberty is associated with a marked increase in testosterone secretion, spermatogenesis and mating behavior. Ejaculation of viable sperm occurs at 4 to 6 months of age, and young bucks have 40 to $60 \%$ of their mature weights. Despite the age of sexual maturity linked to breed, it generally occurs 10-12 months old of age (Demir et al., 2018; Hafez \&Hafez, 2000; Chakraborty et al., 1989). During the breeding season, does undergo several successive estrus cycles and the number of these cycles depends on the length of the breeding season and goat breed. In goats, the length of the estrus cycle is average 17 days but varying from 17 to 25 days. In this period, copulation usually occurs before ovulation, thus sperm are presented in the oviduct and also stored in the cervix, up to 3 days, and are incessantly released into the uterus, where they survive for 
about 30 hours by this time. The embryo is implanted in the uterus 18 to 22 days after the onset of estrus and the length of gestation for the most breed of goats is an average of 144 days (Fatet et al., 2011; Ridler et al., 2012).

In goat breeding, determining the fertility characteristics of buck and doe has great importance for the reproductive success of the herd. As our focus, determining the fertility of bucks carries the success of fertilization in goat breeding with replacing the missing parts of reproduction for facilities.

\section{Andrological Evaluation Examination}

Although, numerous does are generally bred to a single buck, male fertility has a great importance in reproduction. Therefore, evaluation of male fertility has a priority to reach breeding success (Gebre, 2007; Chacon et al., 1999). In various studies, reproduction in males determined mainly as affected by nutrition, genotype, season, management, and diseases (Dowsett \& Knott, 1996; Bielli et al.,2002; Karagiannidis et al., 2000). For optimal production rates in farms, bucks with high breeding abilities and genetic potential for rapid and efficient growth should be selected. These bucks can be selected by the utilization of an andrological evaluation examination protocol and can enhance the economical value of the herd (Pezzanite et al., 2018). This protocol also helps prevent infertility problems from forming in a herd (Gebre, 2007; Goulet \& Fthenakis, 2010). Andrological evaluation examination, also called breeding soundness examination (BSE), consists of a general physical examination, assessment of mating ability, and a genital tract examination of both the external and internal genitalia (including scrotal circumference measurement), and semen quality evaluation (Ridler et al., 2012; Sathe \& Shipley, 2014; Pezzanite et al., 2018). Semen assessment which includes volume, motility, concentration, and morphology gives a general idea about breeding potential as well as freezability of the sample. Unlike bull andrological examination, buck andrological examination criteria are not yet fully developed or commonly used (Chacon et al., 1999; Kennedy et al., 2002). This evaluation should be done at least one month before the breeding season so that replacement can be possible before it is too late (Gouletsou \& Fthenakis, 2010). However, it should not be forgot that the success of bucks of different ages and breeds undergoing andrological examination is variable.

\section{Physical Examination}

During the physical examination, mainly body condition score (BCS) and structural soundness are assessed under international or local breed criteria. In addition to these parameters, the history of the buck in terms of past diseases and breeding performance should be evaluated systemically. BCS is scaled from 1 to 5 and in terms of reproductive performance and efficacy, the optimal is known to be 3 to 3.5 (Pezzanite et al., 2018; Menegassi et al., 2014). It is also advised that the buck starts the reproductive season with a 3.5 to 4 BCS, as it will use a considerable amount of body weight during the breeding season (Gouletsou \& Fthenakis, 2010). The age has also a crucial role for male fertility; optimal breeding age of bucks is considered to be 6 months to 4 years old (Sathe \&Shipley, 2014). In terms of structural soundness feet and legs have the utmost importance. Along with the health of hooves; teeth and eyes are substantial parameters. Other diseases such as pneumonia, internal or external parasites, and especially brucellosis should also be checked (Pezzanite et al., 2018). All breeder males should be also tested serologically for the following agents which are the main causes of infertility in males: Actinobacillus seminis, A. actinomycetemcomitans, Histophilus ovis, Haemophilus spp., Corynebacterium pseudotuberculosis ovis, B. melitensis and Chlamidophila abortus (Sathe \&Shipley, 2014). Additionally, in order to protect the health of the herd and prevent possible aborts and orchitis, it is necessary to take precautions such as vaccination or the eliminating sick animals from the herd against viral infections (Border Disease (Pestivirus), Bluetongue (Orbivirus)) and parasitic infestations (Toxoplasmosis (Toxoplasma gondii)) that can be related by copulation (Menzies, 2012; Goulet \& Fthenakis, 2015).

\section{Examination of Reproductive Organs}

This stage of andrological examination includes observation and palpation of penis, prepuce, scrotum, testis, and epididymis as well as epididymal measurements.

Anatomically, the male reproductive system consists of a pair of extra-abdominally located testes suspended in the scrotum, a fibroelastic penis, and accessory sex glands. The testes are already placed in the scrotum at the time of birth (Gier \& Marion, 1970). Testes suspend vertically in the scrotum with the head of the epididymis located at the proximal end of the testes and its tail extending towards caudal poles. The testes of a buck weigh approximately 130-160 grams each. Scrotal circumference of a buck should be $28 \mathrm{~cm}$ and above, although it depends on various factors such as breed, age and body weight (Ridler et al., 2012; Tibary, 2018). The penis has a sigmoid flexure located caudal to the spermatic cord and an urethral process is located to project 2-3 cm beyond the glans penis (Sathe \& Shipley, 2014). Furthermore, bucks have all three accessory sex glands, vesicula seminalis being the largest. The prostate is disseminated and surrounds the wall of the pelvic urethra. 
A pair of bulbourethral glands are situated caudal to the prostate and on the dorsal surface of the urethra (Haigh, 2007). All observable parts of this system should be normal and in harmony with other body systems.

The prepuce and penis should be both inspected visually and by palpation to make sure there are no signs of injury, adhesions, or other pathologies. Palpation of the accessory glands is not as easily done as in bulls; however, it can be done using one or two fingers or by transrectal ultrasonography (Tekin et al.,2019). Testicular traits are properties correlated with sperm production and animal fertility. Scrotal shape and content are parameters closely related to fertility parameters (Gebre, 2007; Sathe \&Shipley, 2014; Coulter \& Foote, 1977; Ott \& Memon, 1980). During palpation of testicles and scrotum; the testes should be firm, movable within the scrotum, and similar in size. During this examination, epididymis should also be palpated in terms of any hardening or swelling as it can be an indicator of important diseases such as brucellosis. Scrotal circumference and testicular consistency are used to determine reproductive capacity because the scrotal circumference is a method of measuring testicular mass and when combined with testicular consistency it can be an indirect indicator of spermatogenetic capacity (Gebre, 2007; Ridler et al., 2012; Sathe \&Shipley, 2014; Gouletsou \& Fthenakis, 2010; Daudu, 1984, Pezzanite et al., 2018; Filazi et al., 2017) (Figure 1).

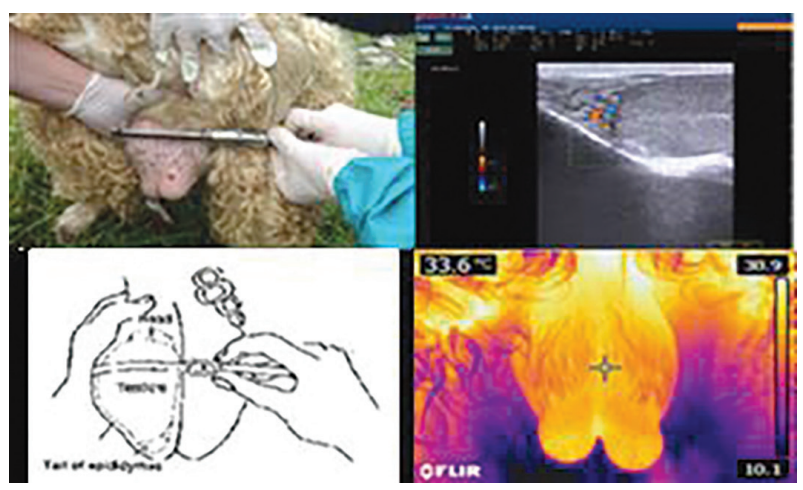

Figure 1: A: Testicular length measurement, B: Ultrasonographic Imaging, C: Circumference measurement, D: Testicular thermography imaging (Daskin et al., 2015).

It was also shown that scrotal circumference is correlated to both age and body weight, with the latter being more significant (Sathe \&Shipley, 2014; Pezzanite et al., 2018). Recently additional procedures have been introduced in this part of the andrological evaluation. These procedures include ultrasonographic imaging of the testes (Sathe \&Shipley, 2014; Gouletsou \& Fthenakis, 2010). Up to date, ultrasonographic imaging has been used in bucks to determine testicular and epididymal measurements and testicular degeneration
(Raji et al.,2016; Ahmad \& Noakes, 1995)(Figure 1). Testicular echo-texture can be used to understand fertility. Healthy, normal buck testes are homogenously echogenic (Ahmad et al.,1991). The mineralization within the testicular parenchyma can be seen using ultrasonographic monitoring with dense hyperechoic areas and acoustic shadowing (Ahmad \& Noakes, 1995). Another option was introduced to the examination of reproductive organs: Thermography. Even though no difference in terms of scrotal temperature was observed among bucks examined (Daskin et al., 2015), this method may give insights about inflammation in the area (Figure 1). Thus, further research on this topic is required.

\section{Semen Analyses}

Semen collection and analyses form the last part of an andrological evaluation examination (Tirpan \& Tekin, 2015). There are two methods generally used for collecting semen from the buck: using artificial vagina or electro-ejaculator (Sathe \&Shipley, 2014). Recently, a novel semen collection method was also described: Transrectal digital massage. In this method, after the feces is removed from the rectum, the seminal vesicles and ampulla are located. On this part of the reproductive organs, back and forth vigorous motion is applied and is continued for up to 5 minutes and thus semen is collected (Tekin et al.,2017). It is the best time to collect semen is during the breeding season. For the artificial vagina method, the artificial vagina should consist of a hose $20-25 \mathrm{~cm}$ in length and 5 to $7 \mathrm{~cm}$ in diameter, with a rubber liner. It is critical to have the interlining lubricated, with the temperature of the artificial vagina approximately $39{ }^{\circ} \mathrm{C}$. As the buck mounts the doe, his penis is gently guided inside the artificial vagina. It is also important to an artificial vagina to have optimal pressure. The glass collecting tube warm also should be kept $37^{\circ} \mathrm{C}$ to avoid cold shock until the semen evaluation. (Sathe \&Shipley, 2014; Hafez \&Hafez, 2000). In the other method, electroejaculation is usually preferred in bucks that are not trained for the artificial vagina. This is an easy to use method for the practitioner if the animal is well restrained or sedated, however, the semen sample obtained is not always in the optimal state. The electro ejaculator procedure is applied by putting a bipolar electrical probe into the buck's rectum. Low voltage electrical stimulation is given for 2 to 4 seconds at 10 to 20 seconds interim until ejaculation occurs. The sample collected using this method may be tainted with urine, may have a high volume but low concentration or higher concentrations of sodium and potassium (Sathe \&Shipley, 2014). Semen volume varies considering the collection method. Fewer volumes are provided from artificial vagina comparing to electroejaculation collec- 
tions. However, the electroejaculation method has several disadvantages as mentioned before.

Semen quality is mainly determined by the evaluation of spermatozoa motility, concentration, and morphology (Ott \&Memon, 1980). In general, the minimal standards for the classification of buck semen samples are at least $85 \%$ motility, less than $10 \%$ morphological abnormalities, 6 to $10 \times 10^{8}$ sperm per $\mathrm{ml}$, and at least 0.5 to $2 \mathrm{ml}$ per ejaculate. A single test does not accurately predict the fertility of the sperm sample, but examining the various physical properties of the sperm can help determine the fertility potential (Kimberling, 1984; Hafez \& Hafez, 2000; Tibary, 2018). In addition, semen evaluation grants a general idea of testicular and epididymal function, allowing the prevention of housing an infertile or subfertile animal (Gebre, 2007; RodriguesMartinez, 2003).

Beside all these classical methods, semen evaluations are mostly carried out by ancillary evaluation methods (computer-assisted semen analyse system and flow cytometry etc.) (Gürler et al.,2012).

\section{Ancillary Semen Evaluation Methods}

Various methods have been used to evaluate sperm ancillary. Some of them are electron microscopy, sperm chromatin structure assay (SCSA), flow cytometry, and computer-assisted semen analyses system (CASA). Flow cytometry and CASA are two methods that used commonly and enable sperm to be examined in many ways in detail (Hafez \& Hafez, 2000, Korkmaz \& Cil, 2020) (Figure 2).

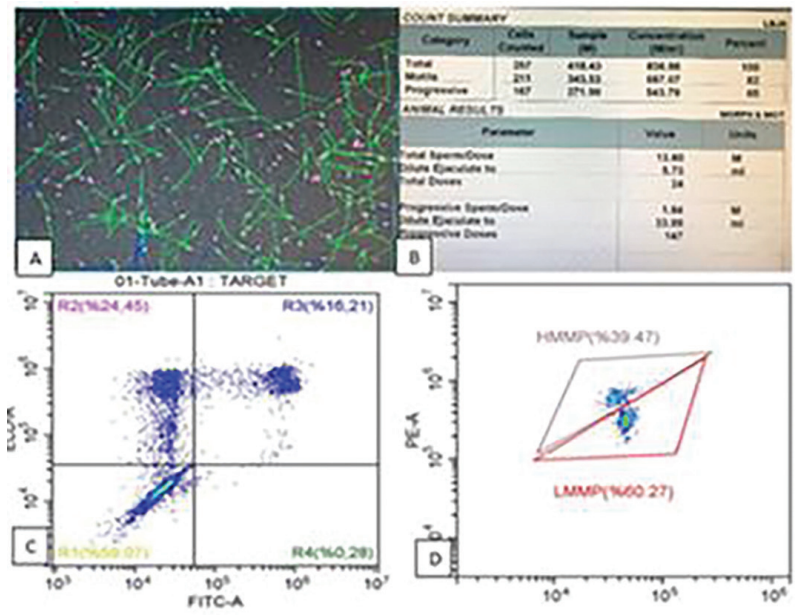

Figure 2: A-B: CASA morphometry and motility analysis, C: Flow cytometric PMAI (Plasma membrane and acrosome integrity) analysis, D: Flow cytometric MMP (Mitochondrial membrane potential) analysis.

\section{Computer Assisted Semen Analyses (CASA)}

CASA is a functional and useful method to reveal sperm populations and subpopulations in an ejaculate. Determination of motility and kinetic parameters of sperm in the ejaculate shows whether they are suitable for freezing and insemination (Tsakmakidis, 2010). These parameters obtained with CASA have been associated with fertility in many studies. The main parameters we can obtain regarding sperm populations with CASA are total motility, progressive motility, VAP (Average path velocity), VSL (Progressive velocity), VCL (Curvilinear velocity), BCF (Beat frequency), STR (Straightness), LIN (Linearity), ALH (Lateral head amplitude), etc. values. These parameters give us an idea of the sperm ability for fertility, and the power of advance in the female genital tract (Hirano et al., 2001). When evaluating goat sperm in the CASA system, the point to be considered to obtain an objective result is the selection of specific settings for the buck. However, the values that obtain from the assessment from these systems should be evaluated with minimum and maximum limits for buck semen (Palacin et al., 2013; Tekin \& Daşkin, 2016; Anand et al., 2016).

\section{Flow Cytometry}

Flow cytometry is often used in andrology laboratories to use for sperm concentration, plasma membrane and acrosome integrity, apoptosis, mitochondrial membrane potential, the capacitation, oxidative stress, lipid peroxidation, DNA integrity analyzes (Korkmaz \& Cil 2020). The purpose of these analyzes is to determine the quality of sperm like all other analyzes. Flow cytometry allows the objective, rapid and simultaneous analysis of several properties in a large number mass of spermatozoa, suggesting that the results of flow cytometric analysis may allow the estimation of the fertility of a semen sample. The results to be obtained from flow cytometry analysis make it easy to estimate the fertility of the semen sample with its reliable and rapid values (Peterson et al., 2007; Tsakmakidis, 2010).

\section{Assisted Reproductive Techniques}

Up-to-date, assisted reproductive techniques frequently used in goats include; synchronization of estrus and ovulation, estrus detection methods, and different insemination techniques. Controlling the reproduction of goats by inducing ovulation via hormonal treatments, manipulation of photoperiod, modulation of estrus cycles brings it about group kidding over a limited period (Sathe \&Shipley, 2014). Goat reproduction management presents these main advantages; synchronizing pregnancies to form a kidding period in a selected season 
and management of genetic resources (Sathe \&Shipley, 2014).

Although all of the artificial insemination methods used in goats have their advantages and disadvantages, the methods used can be listed as follows: vaginal, cervical, transcervical, and laparoscopic, or intrauterine (Daskin et al.,2016). In goats, artificial insemination is usually performed using fresh semen because of the hardships faced during freezing or chilling semen (Chesh et al., 2012). When processing goat semen Trisegg yolk-based extenders are most commonly using agents. Since semen cryopreservation is a valuable technique for goat production allowing semen to be stored for later use (Konyalı et al., 2013), researchers are still trying (1) different extenders (Roof et al., Küçük et al., 2014; Yodmingkwan et al., 2016), (2) freezing protocols (Küçük et al., 2014; Salmon et al., 2017; Inanç et al., 2017) and (3) additives (Konyalı et al., 2013; Salmon et al., 2017) to increase cryo survival of goat semen. If the doe is synchronized; the optimal timing for insemination, including laparoscopic procedure, is usually around 45 hours after progestagen device removal (Cseh et al., 2012). Artificial insemination in goats results in acceptable pregnancy rates when fresh semen is used for vaginal or intra-cervical insemination and frozen semen is used for trans-cervical intrauterine or laparoscopic insemination. Insemination with fresh semen results in pregnancy rates close to natural mating while cervical insemination with frozen semen does not yield satisfactory results (Tirpan et al., 2017; Tirpan et al.,2019). With the laparoscopic insemination technique recently developed, better and more consistent pregnancy rates may be achieved even with frozen semen. Cervical insemination is the most preferred method in goats (Cseh et al., 2012).

\section{Conclusions}

In conclusion, the usage of the andrological examination technique carries the utmost importance in the selection of breeder bucks. The common herd reproductive systems have been used in goat breeding is uncontrolled natural breeding. In such systems, bucks and does are kept together in the same environment regardless of their reproductive characteristics. One step further, in herds where limited controlled natural mating is applied, goats are selected as breeders according to their phenotypic features. However, a little attention is given to the fertility characteristics of the female, and the male andrological and spermatological evaluation can bring success. With enhancing technology; ultrasonography, thermography, computer-assisted methods, and flow cytometry devices finding their place among andrological examinations aid in the better determination of bucks' breeder values. By means of these technologies integrating with andrological examination systematics, parameters such as genetic advance, determination of hereditary and contagious diseases, litter size, estimation of breeding value can be determined more healthily and contribute to the breeding of animals of economic value. The semen collected from bucks of which breeding values are revealed by innovative techniques can be used to inseminate females and reaching genetically superior herds is simplified. With this vision in mind, future research in determining easily applicable technologies and forming a species-specific database should be pursued.

\section{References}

Ahmad, N., \& Noakes, D. E. (1995). Ultrasound imaging in determining the presence of testicular degeneration in two male goats. British Veterinary Journal, 151: p.101-110.

Ahmad, N., Noakes, D. E., \& Subandrıo, A. L. (1991). B-mode real time ultrasonographic imaging of the testis and epididymis of sheep and goats. Veterinary Record, 128: p.491-496.

Anand, M., Yadav, S., Kumar, J., \& Madan, A. K. (2016). Assessment of motion characteristics and path velocities exhibited by barbari buck spermatozoa. Veterinary Practitioner, 17(2), 263-264.

Bielli, A., Pérez, R., Pedrana, G., Milton, J., López, A., Blackberry, M. A., Duncombe, G., Rodriguez-Martinez, H., \& Martin, G. B. (2002). Low maternal nutrition during pregnancy reduces the number of sertoli cells in the newborn lamb. Reproduction Fertility Development, 14: p.333-337.

Chacon, J., Perez, E., Muller, E., Söderquist, L., \& Rodriguez-Martinez, H. (1999). Breeding soundness evaluation of extensively managed bulls in Costa Rica. Theriogenology, 52: p.221-231.

Chakraborty, P. K., Stuart L. D., \& Brown J. L. (1989). Puberty in the male Nubian goat: serum concentrations of LH, FSH and testosterone from birth through puberty and semen characteristics at sexual maturity. Animal Reproduction Science, 20:91.

Coulter, G. H., \& Foote, R. H. (1977). Relationship of body weight to testicular size and consistency in growing Holstein bulls. Journal of Animal Science, 44: p.1076-1079.

Cseh, S., Faigl, V., \& Amiridis, G. S. (2012). Semen provessing and artificial insemination in health management of small ruminants. Animal Reproduction Science, 130: p.187-192.

Daskin, A., Stelletta, C., Pascale, L., Oztutar F., Alemdar, H., Turri, F., Tirpan, M. B., Vencato, J., Tekin, K., \& Pizzi, F. (2015). “Integrated Andrological Evaluation in Angora Goat." Animal Reproduction, 12(3): 792.

Daskin, A., Tekin, K., Tırpan, M. B., Inanç, M. E., Çil, B., \& Alemdar, $H$. (2016). The effect of different insemination techniques and cervical conformation index on fertility rates in Angora goat. Animal Reproduction Science, 100(169), 116.

Daudu, C. S. (1984). Spermatozoa output, testicular sperm reserve and epididymal storage capacity of the Red Sokoto goats indigenous to northern Nigeria. Theriogenology, 21: p.317-324.

Delgadillo, J. A., Malpaux, B., \& Chemineau, P. (1997). La reproduction des caprins dans les zones tropicales et subtropicales, INRA, Productions Animales, 10(1): p.33-41. 
Demir, H., Elmaz, Ö., \& Cerit, H. (2018). Keçilerde puberta ve eşeysel olgunluk yaşının belirlenmesi ile ilgili araştırmalar. Uludağ Üniversitesi Veteriner Fakültesi Dergisi, (January 2019).

https://doi.org/10.30782/uluvfd.415214.

Dowsett, K. F. \& Knott, L. M. (1996). The influence of age and breed on stallion semen. Theriogenology, 46: p.397-412.

Fatet, A., Pellicer-Rubio, M. T., \& Leboeuf, B. (2011). Reproductive cycle of goats. Animal Reproduction Science, 124: p.211-219.

Filazi, A., Yurdakök, B., Tekin K., Tırpan, M. B., \& Daşkın, A. (2017). In vitro toxicity of some pesticides on goat and dog spermatozoa. Kafkas Üniversitesi Veteriner Fakültesi Dergisi, 23(2).

Gebre, Y. M. (2007). Reproductive traits in Ethiopian male goats with special reference to breed and nutrition. Doctoral thesis, Swedish University of Agricultural Sciences, Uppsala.

Gier, H. T. \& Marion, G. B. (1970). The Testis Development, Anatomy and Physiology, Volume I, Academic Press, New York and London.

Gouletsou, P. G., \& Fthenakis, G. C. (2010). Clinical evaluation of reproductive ability of rams. Small Ruminant Research, 92: p.45-51.

Gouletsou, P. G., \& Fthenakis, G. C. (2015). Microbial diseases of the genital system of rams or bucks. Veterinary Microbiology, 181: $130-135$

Gürler, H., Siuda, M., Göbel, H., Tırpan, B., Leiding, C., \& Bollwein, H. (2012). Effects of a prolongation of equilibration time up to 96 hours on quality of cryopreserved bovine sperm. Reproduction in Domestic Animals, 47(Supplement 2): p.25.

Hafez, E. S. E., \& Hafez, B., (2000). Reproduction in Farm Animals. 7th Edition. ISBN 0-683-30577-8.

Haigh, J. C. (2007). Current Therapy in Large Animal Theriogenology, Second Edition. Saunders Elsevier, Missouri.

Hirano, Y., Shibahara, H., Obara, H., Suzuki, T., Takamizawa, S., Yamaguchi, C., \& Sato, I. (2001). ANDROLOGY: Relationships Between Sperm Motility Characteristics Assessed by the Computer-Aided Sperm Analysis (CASA) and Fertilization Rates In Vitro. Journal of Assisted Reproduction and Genetics, 18(4), 215-220. https://doi.org/10.1023/A:1009420432234.

Inanç, M. E., Tekin, K., Olğaç, K. T., Tırpan, M. B., Alemdar, H., Çil, B., Kaya, U., Stelletta, C., \& Daşkın, A. (2017). Effects of region and invidualism traits on sperm freezeability of Angora Goats. Journal of Turkish Veterinary Medical Society, 88, 31-39.

Karagiannidis, A., Varsakeli, S., \& Karatzas, G. (2000). Characteristics and seasonal variations in the semen of Alpine, Saanen and Damascus goat bucks born and raised in Greece. Theriogenology, 53: p.1285-1293.

Kennedy, S. P., Spitzer, J. C., Hopkins, F. M., Higdon, H. L., \& Bridges, W. C. (2002). Breeding soundness evaluations of 3648 yearling beef bulls using the 1993 society for Theriogenology guidelines. Theriogenology, 58: p.947-961.

Kimberling, C. V. (1984). Breeding Soundness Evaluation of Rams. Journal of American Veterinary Medical Association, 185: 325325.

Konyalı, C., Tomas, C., Blanch, E., Gomez, E. A., Graham, J. K., \& Moce, E. (2013). Optimizing conditions for treating goat semen with cholesterol-loaded cyclodextrins prior to freezing to improve cryosurvival. Cryobiology, 67: p.124-131.
Küçük, N., Aksoy, M., Uçan, U., Ahmad, E., Naseer, Z., Ceylan, A., \& Serin, i. (2014). Comparison of two different cryopreservation protocols for freezing goat semen. Cryobiology, 68: p.327-331.

Menegassi, S. R. O., Barcellos, J. O. J., Borges, J. B. S., Canozzi, M. E. A., Perpolli, V., Junior, C. K., Lopes, F. G., \& Cervo, H. J. (2014). Breeding soundness examination: Understanding the causes of examination failure in young and mature rams. International Journal of Plant and Animal Sciences, 2(2): p.98-104.

Menzies, P. I. (2012). Vaccination programs for reproductive disorders of small ruminants. Anim. Reprod. Sci. 130, 162-172.

Ott, R. S., \& Memon, M. A. (1980). Breeding soundness examinations of rams and bucks, a review, Theriogenology, 13(2): p.155-164.

Palacín, I., Vicente-Fiel, S., Santolaria, P., \& Yániz, J. L. (2013). Standardization of CASA sperm motility assessment in the ram. Small Ruminant Research, 112(1-3), 128-135. https://doi. org/10.1016/j.smallrumres.2012.12.014

Peterson, K., Kappen, M. A. P. M., Ursem, P. J. F., Nöthling, J. O., Colenbrander, B., \& Gadella, B. M. (2007). Microscopic and flow cytometric semen assessment of Dutch Al-bucks: Effect of semen processing procedures and their correlation to fertility. Theriogenology, 67(4), 863-871. https://doi.org/10.1016/j. theriogenology.2006.11.003.

Pezzanite, L., Bridges, A., Neary, M., \& Hutchens, T. (2018). Breeding soundness examinations of rams and bucks, Purdue Extension. Animal Sciences [cited 201826 February]; Available from: https://www.extension.purdue.edu/extmedia/AS/AS599-W.pdf.

Raji, L. O., Ajala, O. O., \& Ameen, S. A. (2016). Testicular ultrasound as a breeding soundness examination and biometric tool for West african dwarf buck goats. Slovak Journal of Animal Science, (1): p.8-16

Ridler, A. L., Smith, S. L., \& West D. M. (2012). Ram and buck management. Animal Repdoruction Science, 130: p.180-183.

Rodriguez-Martinez, H. (2003). Laboratory semen assessment and prediction of fertility: still utopia? Reproduction in Domestic Animals, 38: p.312-318.

Roof, D. J., Bowley, S., Price, L. L., \& Matsas, D. J. (2012). Comparison of two commercial extenders for cryopreservation of goat semen without sperm washing. Theriogenology, 77: p.412-420.

Salmon, V. M., Lerlerc, P., \& Bailey, J. L. (2017). Novel technical strategies to optimize cryopreservation of goat semen using cholesterol-loaded cyclodextrin. Cryobiology, 74: p.19-24.

Sathe, S., \& Shipley, C. (2014). Animal Andrology: Theories and Applications. Wagga Wagga, Australia.

Tekin, K., \& Daşkin, A. (2016). Effect of different extenders on motility and some sperm kinematics parameters in Norduz goat semen. Turkish Journal of Veterinary and Animal Sciences, 40(4), 490-495. https://doi.org/10.3906/vet-1509-5

Tekin, K., Çil, B., Alemdar, H., Olğaç, K. T., Tırpan, M. B., Daskin, A., \& Stellatta, C. (2019). Semen collection by trans-rectal digital stimulation and insemination campaign in goat. Andrologia, 52(2), e13458. https://doi.org/10.1111/and.13458.

Tekin, K., Stelletta, C., Çil, B., Tırpan, M. B., Olğaç, K. T., Alemdar, H., \& Daşkın, A. (2017). Trans-rectal semen collection and artificial insemination in Angora goat. Reproduction in Domestic Animals, 52(3): 64 
Tirpan, M. B., \& Tekin, N. (2015). Effects of boron (sodium pentaborate), added instead of Tris components, on freezing and post-thaw quality of Angora buck semen. Ankara Üniversitesi Veteriner Fakültesi Dergisi, 62, 295-302.

Tırpan, M. B., Tekin, K., Çil, B., Alemdar, H., İnanç, M. E., Olğaç, K. T., Stelletta, C., \& Daşkın, A. (2019). The effects of different PMSG doses on estrus behavior and pregnancy rate in Angora goats. Animal, 13(3), 564-569., Doi: 10.1017/ S1751731118001908.

Tırpan, M. B., Tekin, K., Stelletta, C., \& Daşkın, A. (2017). Intracervical artificial insemination of Saanen goats in different breeding age with frozen- thawed semen. 21th Annual Conference of the European Society for Domestic Animal Reproduction, 52(3), 138-138.
Tibary, A., Boukhliq R., El Allali K. (2018). Ram and Buck Breeding Soundness Examination. Revue Marocaine des Sciences Agronomiques et Vétérinaires. 6: 241-255.

Tsakmakidis, I. A. (2010). Ram semen evaluation: Development and efficiency of modern techniques. Small Ruminant Research, 92(1-3), 126-130. https://doi.org/10.1016/j.smallrumres.2010.04.017

Yodmingkwan, P., Guntaprom, S., Jaksamrit, J., \& Lertchunhakiat, K. (2016). Effects of extenders on fresh and freezing semen of boer goat. Agriculture and Agricultural Science Procedia, 11: p.125-130. 